\title{
Multi-Residue Determination of Pesticides in Vegetables on Dalian Market by Gas Chromatograph, 2009-10
}

\begin{abstract}
This paper presents results from surveillance of pesticide multi-residues in vegetables carried out in 2009-10. 420 samples of 10 different types of fresh vegetables were analyzed for their pesticide multi-residue contents using gas chromatograph and NY/T 761-2008 pesticide multi-residue screen methods. The residues exceeded MRLs of forbidden pesticides found were: carbofuran 0.110 $\mathrm{mg} / \mathrm{kg}$ (kidney bean) and methamidophos $0.037 \mathrm{mg} / \mathrm{kg}$ (celery) in January 2009, methamidophos $0.037 \mathrm{mg} / \mathrm{kg}$ (tomato) in May 2009, aldicarb $0.013 \mathrm{mg} / \mathrm{kg}$ (kidney bean) in September 2009, omethoate $2.200 \mathrm{mg} / \mathrm{kg}$ (celery) in November 2009, carbofuran $0.052 \mathrm{mg} / \mathrm{kg}$ (green pepper) in April 2010, parathion $0.056 \mathrm{mg} / \mathrm{kg}$ (celery) and carbofuran $0.030 \mathrm{mg} / \mathrm{kg}$ (celery) in July 2010. Also, chlorpyrifos used as unforbidden pesticide was most frequently found above MRL, rape $(0.820 \mathrm{mg} /$ $\mathrm{kg}$ ) and celery $(0.365 \mathrm{mg} / \mathrm{kg})$ in January 2009 , celery $(0.330 \mathrm{mg} / \mathrm{kg})$ in May 2009 , lettuce $(0.298 \mathrm{mg} / \mathrm{kg})$ in September 2009, rape $(0.910 \mathrm{mg} / \mathrm{kg})$ in April 2010 and lettuce $(0.230 \mathrm{mg} / \mathrm{kg})$ in July 2010 . In addition, cypermethrin used as unforbidden pesticide was found above MRL only once in rape $(1.270 \mathrm{mg} / \mathrm{kg})$ in May 2009 and none of unforbidden pesticides above MRL was found in November 2009 and January 2010. Most of the samples (96\%) were up to the national standard.
\end{abstract}

Keywords: Multi-residue; Determination; Pesticides; Vegetables; Gas chromatograph

Received: January 11, 2018; Accepted: March 01, 2018; Published: March 05, 2018

\author{
Liang Fu', \\ Shengzhong Dong', \\ Shiyang Liu' ${ }^{2}$ and \\ Fangxu $\mathrm{Xu}^{1 *}$
}

1 Experimental Teaching Center, Shenyang Normal University, Shenyang, Liaoning, 110034, People's Republic of China

2 Logistics Management Office, Shenyang Pharmaceutical University, Shenyang, Liaoning, 110016, People's Republic of China

\section{*Corresponding author: Fangxu Xu \\ ”xufangxu321@163.com}

Experimental Teaching Center, Shenyang Normal University, Shenyang, Liaoning, 110034, People's Republic of China.

Tel: +862486574436

Citation: Liang Fu, Dong S, Liu S, Fangxu Xu (2018) Multi-Residue Determination of Pesticides in Vegetables on Dalian Market by Gas Chromatograph, 2009-10. J Food Nutr Popul Health Vol.2 No.1:2

\section{Introduction}

Nowadays, a growing demand for safe and nutritional agricultural products requires more green vegetables grown without the usage of pesticides [1-7]. Over 800 pesticides belonging to over 100 different chemical classes are extensively used to protect crops before and after harvest from infestation by pests and plant diseases in agriculture all over the world [1,2]. Although pesticides play an important role in increasing production and ensuring quality in agricultural practice, residues will evaporate into the air, flow into the rivers, settle in the soil, pollute the productions and transfer to the human bodies, which will cause potential harm to the human being and pose a major threat to biodiversity [3]. Therefore, the issue of produce security, environmental pollution and human health that caused by the usage of pesticides are seriously concerned worldwide.
Since the 21st century, numerous researches on the effects of pesticide multi-residue to quality and security of agricultural products have been carried up successively [5]. The Southeastern Poland monitoring programme for $2004-05$ covered 747 samples of 39 different types of fresh fruits and vegetables which were analyzed for pesticide multi-residue contents, and there were 27 samples (3.6\%) residues exceeded national MRLs [8]. A total of 4404 samples of fruits and vegetables (34\% of Danish origin and $66 \%$ from other countries) were analyzed for pesticide multiresidue contents (2000-01), and approximately 89 pesticides were detected which were more frequently found in fruit (60\%) than in vegetables (18\%) [6]. The present study reports the results from Dalian market (2009-10) of an on-going vegetable monitoring programme conducted by Liaoning Province Agriculture Academic Sciences, is aimed at ensuring that consumers are not exposed to unacceptable pesticide multi-residue levels. 


\section{Materials and Methods}

\section{Samples collection}

The seasons and producing areas are influencing factors of pesticide types and pesticide multi-residue. The sampling plan was performed on the basis of guideline on sampling for pesticide multi-residue analysis (NY/T 789-2004). We did the random sampling of 60 samples each time and the number was difference for each type of vegetables. A total of 420 samples of 10 different types of vegetables (kidney bean, Chinese cabbage, eggplant, tomato, celery, lettuce, rape, cucumber, cabbage and green pepper) were taken from wholesale markets, hypermarkets and farmer's markets in January, May, September and November of 2009 and in January, April and July of 2010, respectively (Table 1). After sampling, the unwashed and unpeeled samples were immediately homogenate processing with a waring blender and freezing at $-18^{\circ} \mathrm{C}$ to determine and analyse.

\section{Pesticide selection}

In accordance with Regulations of the People's Republic of China on the Control of Agricultural Chemicals and Varieties of Forbidden and Restricted Pesticide, 27 kinds of pesticide were detected in vegetables of Dalian market including organophosphorus pesticides (methamidophos, omethoate, parathion, parathionmethyl, dichlorvos, chlorpyrifos, sumithion, phosmet, phorate, monocrotophos, malathion and fenthion), organochlorine and pyrethroid pesticides (triadimefon, cypermethrin, fenvalerate, fenpropathrin, cyfluthrin, cyhalothrin, deltamethrin, bifenthrin and chlorothalonil) and carbamate pesticides (metalaxyl, pirimicarb, carbaryl, aldicarb, carbofuran and methomyl). A total of 8 kinds of forbidden pesticide (methamidophos, omethoate, parathion, parathion-methyl, phorate, monocrotophos, aldicarb, carbofuran) were specially detected.

\section{Extraction}

The samples (25 g) were accurately weighed into a $100 \mathrm{ml}$ polypropylene centrifuge tube and extracted with $50 \mathrm{ml}$ acetonitrile, a high-speed homogenate machine was used to blend at $20000 \mathrm{rpm}$ for $2 \mathrm{~min}$. Then, the mixture was filtered through a piece of filter paper and the combined filtrate (about 40-50 ml) was collected into a $100 \mathrm{ml}$ measuring cylinder containing $5-7 \mathrm{~g} \mathrm{NaCl}$. The measuring cylinder was sealed up with a plug and oscillated tempestuously for $1 \mathrm{~min}$. After that, left it to stand for $30 \mathrm{~min}$ at room temperature to make acetonitrile phase and water phase stratification. A total of $10 \mathrm{ml}$ acetonitrile were sucked up to a $150 \mathrm{ml}$ beaker which was kept in a water bath at $80^{\circ} \mathrm{C}$ ventilating with nitrogen or air slowly for evaporating to nearly dryness.

\section{Purification}

The methods of purification are different among organophosphorus pesticides, organochlorine and pyrethroid pesticides and carbamate pesticides. The specific content and operation methods are brief introduced as follows.

Organophosphorus pesticides: Acetone $(2 \mathrm{ml})$ was added into the above residue and the beaker was covered with aluminium foil for purifying. The ready solution was transfered to a $15 \mathrm{ml}$ scale centrifugal tube absolutely and acetone (about $3 \mathrm{ml}$ ) was used to wash the beaker for three times. The total volume collected was adjusted to exactly $5 \mathrm{ml}$ and blended with a whirlpool mixer. The samples were filtrated with filter membrane $(0.22 \mu \mathrm{m})$ before determination.

Organochlorine and pyrethroid pesticides: An aliquot of 10 $\mathrm{ml} \mathrm{n}$-hexane was added and the beaker was covered with aluminium foil for subsequent use. The Florisil PR column was eluted beforehand and conditioning using $5 \mathrm{ml}$ mixed solution of acetone and $\mathrm{n}$-hexane (mass fraction 10:90) and $5 \mathrm{ml} n$-hexane successively. When the dissolvent reached to the surface of column adsorption layer, the above sample was immediately poured into Florisil PR column and recovered with a $15 \mathrm{ml}$ scale centrifugal tube. The beaker was washed twice with $5 \mathrm{ml}$ mixed solution of acetone and $n$-hexane (mass fraction 10:90), then the effluent solution went through Florisil PR column again. The scale centrifugal tube containing the whole leacheate was laid in a pressure blowing concentrator at $50^{\circ} \mathrm{C}$ for evaporating to less than $5 \mathrm{ml}$ and scaled to $5 \mathrm{ml}$ with $\mathrm{n}$-hexane. After that the mixed solution was blended with a whirlpool mixer. The samples were filtrated with filter membrane $(0.22 \mu \mathrm{m})$ before determination.

Carbamate pesticedes: Mixed solution $(2 \mathrm{ml}$ ) of methyl alcohol and dichloromethane in a ratio of 1:99 (mass fraction) was added and the beaker was covered with aluminium foil. The

Table 1 Number of random sampling in 2009-10.

\begin{tabular}{|c|c|c|c|c|c|c|c|c|}
\hline \multirow{2}{*}{ Commodity } & \multicolumn{8}{|c|}{ Number } \\
\hline & January, 2009 & May, 2009 & September, 2009 & November, 2009 & January, 2010 & April, 2010 & July, 2010 & Total \\
\hline Kidney bean & 8 & 8 & 8 & 7 & 7 & 6 & 8 & 52 \\
\hline Chinese cabbage & 0 & 0 & 0 & 6 & 0 & 0 & 0 & 6 \\
\hline Tomato & 7 & 7 & 8 & 6 & 8 & 6 & 1 & 43 \\
\hline Cucumber & 8 & 7 & 8 & 10 & 8 & 6 & 6 & 53 \\
\hline Cabbage & 8 & 8 & 6 & 9 & 8 & 7 & 8 & 54 \\
\hline Eggplant & 7 & 8 & 8 & 6 & 7 & 6 & 3 & 45 \\
\hline Celery & 7 & 6 & 8 & 5 & 6 & 6 & 11 & 49 \\
\hline Green pepper & 0 & 0 & 0 & 0 & 0 & 7 & 4 & 11 \\
\hline Lettuce & 8 & 8 & 7 & 6 & 8 & 9 & 9 & 55 \\
\hline Rape & 7 & 8 & 7 & 5 & 8 & 7 & 10 & 52 \\
\hline Total & 60 & 60 & 60 & 60 & 60 & 60 & 60 & 420 \\
\hline
\end{tabular}


amino column was eluted in advance and conditioning using $4 \mathrm{ml}$ mixed solution of methyl alcohol and dichloromethane (mass fraction 1:99). The above sample was rapidly added into the amino column as the dissolvent reached to the surface of column adsorption layer. The eluent was gathered with a $15 \mathrm{ml}$ centrifuge tube and $2 \mathrm{ml}$ mixed solution of methyl alcohol and dichloromethane (mass fraction 1:99) was used to wash the beaker twice, then the eluent went through the amino column and combined. The total solution collected was evaporated to dryness in a pressure blowing concentrator at $50^{\circ} \mathrm{C}$ under a nitrogen stream. Afterwards, the residue was accurately scaled to $2.5 \mathrm{ml}$ with methyl alcohol and mixed with a whirlpool mixer for detecting.

\section{Analytical methods}

By the method of NY/T 761-2008 pesticide multi-residue screen methods for determination of organophosphorus pesticides, organochlorine pesticides, pyrethroid pesticides and carbamate pesticedes in vegetables and fruits, the samples were evaluated with Agilent $6890 \mathrm{~N}$ gas chromatograph (with detectors of FPD, ECD and NPD). The chromatographic columns and SPE were from Agilen and the reagents used in the tests were all analytical reagents completely. Each sample determined twice parallelly, taking the means as the report results.

Organophosphorus pesticides: A gas chromatograph system (Agilent 6890N, Palo Alto, USA) equipped with an autosampler was used to analyse the residue of organophosphorus pesticides. The gas chromatograph separation was performed using a $50 \%$ poly phenyl dimethyl siloxane column (DB-17, $30 \mathrm{~m} \times 0.53 \mathrm{~mm} \times$ $1.0 \mu \mathrm{m})(\mathrm{A})$ and a $100 \%$ poly dimethyl siloxane column (HP-1, 30 $\mathrm{m} \times 0.53 \mathrm{~mm} \times 1.5 \mu \mathrm{m})(\mathrm{B})$ with the injector temperature of $220^{\circ} \mathrm{C}$ and the detector temperature of $250^{\circ} \mathrm{C}$. The temperature of the column was programmed as follows: $150^{\circ} \mathrm{C}(2 \mathrm{~min}) ; 8^{\circ} \mathrm{C} / \mathrm{min}$ to $250^{\circ} \mathrm{C}$ (12 min). Helium ( $\geq 99.999 \%$ ) was used as a carrier gas at a flow of $10 \mathrm{ml} / \mathrm{min}$, hydrogen ( $\geq 99.999 \%$ ) was used as a burning gas at a flow of $75 \mathrm{ml} / \mathrm{min}$ and the air was used as an aided gas at a flow of $100 \mathrm{ml} / \mathrm{min}$. The sample was divided into two parts and injected by a double autosampler at the same time. The standard solution of $1 \mathrm{ml}$ was injected for comparing. The peak area of sample from column A was compared with the peak area of standard solution for quantitative analysis. If the retention time of the sample from the double columns and standard solution differ with in $\pm 0.05 \mathrm{~min}$, the unknown component could be concluded.

Organochlorine and pyrethroid pesticides: The gas chromatograph separation was performed using a $100 \%$ poly dimethyl siloxane column (HP-1, $30 \mathrm{~m} \times 0.25 \mathrm{~mm} \times 0.25 \mu \mathrm{m})(\mathrm{A})$ and a $50 \%$ poly phenyl dimethyl siloxane column (DB-17, $30 \mathrm{~m} \times$ $0.25 \mathrm{~mm} \times 0.25 \mu \mathrm{m})(\mathrm{B})$ with the injector temperature of $200^{\circ} \mathrm{C}$ and the detector temperature of $320^{\circ} \mathrm{C}$. The temperature of the column was programmed as follows: $150^{\circ} \mathrm{C}(2 \mathrm{~min}) ; 6^{\circ} \mathrm{C} / \mathrm{min}$ to $270^{\circ} \mathrm{C}$ (8 min, $23 \mathrm{~min}$ for deltamethrin). Helium ( $\geq 99.999 \%$ ) was used as a carrier gas at a flow of $1 \mathrm{ml} / \mathrm{min}$ and an aided gas at a flow of $60 \mathrm{ml} / \mathrm{min}$. The quantitative and qualitative analytical methods were the same as those of organophosphorus pesticides.
Carbamate pesticides: Analytical column (C8, $4.6 \mathrm{~mm} \times 25 \mathrm{~cm} \times$ $5 \mu \mathrm{m}$ or $\mathrm{C} 18,4.6 \mathrm{~mm} \times 25 \mathrm{~cm} \times 5 \mu \mathrm{m}$ ) was used for determination of carbamate pesticides with the column temperature of $42^{\circ} \mathrm{C}$ and fluorescence detector wavelength of $330 \mathrm{~nm}$ and $465 \mathrm{~nm}$. The post-column derivatization condition were as follows: 0.05 $\mathrm{mol} / \mathrm{L} \mathrm{NaOH}$, flow rate of $0.3 \mathrm{ml} / \mathrm{min}$, OPA reagent flow rate of $0.3 \mathrm{ml} / \mathrm{min}$, hydrolysis temperature of $100^{\circ} \mathrm{C}$ and derivative temperature of room temperature. The retention time of 20 $\mu$ standard solution and sample were injected for qualitative analysis, however the peak area for qualitative analysis.

\section{Quality assurance procedures}

A gas chromatograph method using an external standard was developed for quantitative analysis (each sample for twice) and double columns for qualitative analysis. The test results were reliable when the standardized recovery reached to $70 \%-130 \%$, whereas if the results out of rang, it needed to retest.

\section{Results and Discussion}

Maximum residue limits (MRLs) are defined as the highest concentrations of pesticide multi-residues $(\mathrm{mg} / \mathrm{kg})$. However, MRLs are not safety limits, and exposure to residues in excess of an MRL does not automatically imply a hazard to health [8]. Details of pesticide multi-residue $(\mathrm{mg} / \mathrm{kg})$ detected in 2009 10 were provided in Tables 2-8. A total of 420 samples of 10 different types of vegetables were analyzed for their pesticide multi-residue contents.

The samples were analysed for approximately 27 pesticides using gas chromatograph and NY/T 761-2008 pesticide multi-residue screen methods. As seen in Tables 2-8, 8 detections of 5 kinds of forbidden pesticides were detected in various vegetables, carbofuran $0.110 \mathrm{mg} / \mathrm{kg}$ (kidney bean) and methamidophos $0.037 \mathrm{mg} / \mathrm{kg}$ (celery) in January 2009, methamidophos $0.037 \mathrm{mg} /$ $\mathrm{kg}$ (tomato) in May 2009, aldicarb $0.013 \mathrm{mg} / \mathrm{kg}$ (kidney bean) in September 2009, omethoate $2.200 \mathrm{mg} / \mathrm{kg}$ (celery) in November 2009, carbofuran $0.052 \mathrm{mg} / \mathrm{kg}$ (green pepper) in April 2010, parathion $0.056 \mathrm{mg} / \mathrm{kg}$ (celery) and carbofuran $0.030 \mathrm{mg} / \mathrm{kg}$ (celery) in July 2010, none of forbidden pesticides was found in January 2010.

In addition, with regard to unforbidden pesticides, chlorpyrifos was most frequently found above MRL during the 7 sample survey, rape $(0.820 \mathrm{mg} / \mathrm{kg})$ and celery $(0.365 \mathrm{mg} / \mathrm{kg})$ in January 2009 , celery $(0.330 \mathrm{mg} / \mathrm{kg})$ in May 2009 , lettuce $(0.298 \mathrm{mg} / \mathrm{kg})$ in September 2009, rape $(0.910 \mathrm{mg} / \mathrm{kg})$ in April 2010, lettuce $(0.230 \mathrm{mg} / \mathrm{kg})$ in July 2010 . Also, cypermethrin was found above MRL only once in rape $(1.270 \mathrm{mg} / \mathrm{kg})$ in May 2009 and none of unforbidden pesticides exceeding MRL was found in November 2009 and January 2010. In most cases pesticide residues occurred on levels well below MRLs.

Table 9 shows the qualifying rates of random sampling for all vegetables in 2009-10. Results of the surveys presented in table 9 indicate that the average qualifying rate values (97\%) of samples in 2010 were higher than the results (94\%) in 2009. The qualifying rates of cucumber, cabbage and eggplant were all up to $100 \%$ during 2009-10. There was a great deal of improvement in the qualifying rates of celery in 2010 (94\%) versus 2009 (67\%). Also, 
Table 2 Pesticide multi-residue in vegetables analyzed in January, 2009.

\begin{tabular}{|c|c|c|c|c|c|}
\hline Commodity & Pesticide & Detected number & Mean (mg/kg) & $\operatorname{Max}(\mathrm{mg} / \mathrm{kg}$ ) & MRL (mg/kg) \\
\hline \multirow{3}{*}{ Kidney bean } & Chlorpyrifos & 1 & 0.034 & 0.034 & 1 \\
\hline & Chlorothalonil & 2 & 0.013 & 0.021 & 5 \\
\hline & Carbofuran & 1 & 0.110 & 0.110 & 0 \\
\hline \multirow{2}{*}{ Tomato } & Bifenthrin & 2 & 0.004 & 0.005 & 0.5 \\
\hline & Triadimefon & 1 & 0.072 & 0.072 & 0.1 \\
\hline Cucumber & Chlorothalonil & 1 & 0.018 & 0.018 & 5 \\
\hline Cabbage & Metalaxyl & 1 & 0.144 & 0.144 & 0.5 \\
\hline \multirow{4}{*}{ Eggplant } & Chlorpyrifos & 2 & 0.063 & 0.098 & 0.5 \\
\hline & Cypermethrin & 2 & 0.015 & 0.017 & 0.5 \\
\hline & Bifenthrin & 1 & 0.003 & 0.003 & 0.5 \\
\hline & Chlorothalonil & 2 & 0.009 & 0.017 & 5 \\
\hline \multirow{6}{*}{ Celery } & Methamidophos & 1 & 0.037 & 0.037 & 0 \\
\hline & Chlorpyrifos & 3 & 0.365 & 0.540 & 0.05 \\
\hline & Fenpropathrin & 1 & 0.200 & 0.200 & 0.5 \\
\hline & Chlorothalonil & 3 & 1.126 & 1.940 & 5 \\
\hline & Carbaryl & 1 & 0.790 & 0.790 & 2 \\
\hline & Methomyl & 1 & 0.025 & 0.025 & 2 \\
\hline \multirow{3}{*}{ Lettuce } & Chlorpyrifos & 1 & 0.098 & 0.098 & 0.1 \\
\hline & Cyhalothrin & 2 & 0.014 & 0.015 & 0.2 \\
\hline & Chlorothalonil & 1 & 0.002 & 0.002 & 5 \\
\hline \multirow{5}{*}{ Rape } & Chlorpyrifos & 1 & 0.820 & 0.820 & 0.1 \\
\hline & Cypermethrin & 1 & 0.060 & 0.060 & 0.5 \\
\hline & Fenpropathrin & 1 & 0.011 & 0.011 & 0.5 \\
\hline & Cyhalothrin & 1 & 0.003 & 0.003 & 0.2 \\
\hline & Chlorothalonil & 1 & 0.002 & 0.002 & 5 \\
\hline
\end{tabular}

Table 3 Pesticide multi-residue in vegetables analyzed in May, 2009.

\begin{tabular}{|c|c|c|c|c|c|}
\hline Commodity & Pesticide & Detected number & Mean (mg/kg) & $\operatorname{Max}(\mathrm{mg} / \mathrm{kg})$ & MRL (mg/kg) \\
\hline \multirow{2}{*}{ Kidney bean } & Fenvalerate & 1 & 0.042 & 0.042 & 0.2 \\
\hline & Cyfluthrin & 1 & 0.012 & 0.012 & 0.1 \\
\hline \multirow{3}{*}{ Tomato } & Methamidophos & 1 & 0.037 & 0.037 & 0 \\
\hline & Chlorpyrifos & 1 & 0.045 & 0.045 & 0.5 \\
\hline & Cyfluthrin & 1 & 0.034 & 0.034 & 0.1 \\
\hline Cucumber & Chlorothalonil & 1 & 0.005 & 0.004 & 5 \\
\hline Cabbage & Triadimefon & 2 & 0.006 & 0.006 & 0.05 \\
\hline \multirow{2}{*}{ Eggplant } & Chlorothalonil & 1 & 0.004 & 0.003 & 5 \\
\hline & Methomyl & 1 & 0.024 & 0.024 & 2 \\
\hline \multirow{5}{*}{ Celery } & Chlorpyrifos & 1 & 0.330 & 0.330 & 0.05 \\
\hline & Cypermethrin & 1 & 0.240 & 0.240 & 2 \\
\hline & Triadimefon & 1 & 0.011 & 0.011 & 0.1 \\
\hline & Chlorothalonil & 2 & 0.094 & 0.130 & 5 \\
\hline & Metalaxyl & 1 & 0.020 & 0.020 & 0.5 \\
\hline \multirow{6}{*}{ Lettuce } & Chlorpyrifos & 1 & 0.027 & 0.027 & 0.1 \\
\hline & Cypermethrin & 1 & 0.078 & 0.078 & 2 \\
\hline & Fenvalerate & 3 & 0.132 & 0.350 & 0.5 \\
\hline & Triadimefon & 1 & 0.004 & 0.004 & 0.1 \\
\hline & Chlorothalonil & 1 & 0.003 & 0.002 & 5 \\
\hline & Methomyl & 1 & 0.027 & 0.027 & 2 \\
\hline \multirow{4}{*}{ Rape } & Chlorpyrifos & 1 & 0.024 & 0.024 & 0.1 \\
\hline & Cypermethrin & 4 & 0.378 & 1.270 & 0.5 \\
\hline & Chlorothalonil & 1 & 0.006 & 0.006 & 5 \\
\hline & Methomyl & 1 & 0.026 & 0.026 & 2 \\
\hline
\end{tabular}


Table 4 Pesticide multi-residue in vegetables analyzed in September, 2009.

\begin{tabular}{|c|c|c|c|c|c|}
\hline Commodity & Pesticide & Detected number & Mean (mg/kg) & $\operatorname{Max}(\mathrm{mg} / \mathrm{kg})$ & MRL (mg/kg) \\
\hline \multirow{2}{*}{ Kidney bean } & Chlorothalonil & 1 & 0.002 & 0.002 & 5 \\
\hline & Aldicarb & 1 & 0.013 & 0.013 & 0 \\
\hline Tomato & Carbaryl & 2 & 0.049 & 0.080 & 2 \\
\hline Cucumber & Metalaxyl & 2 & 0.020 & 0.020 & 0.5 \\
\hline \multirow{3}{*}{ Cabbage } & Triadimefon & 1 & 0.005 & 0.005 & 0.05 \\
\hline & Carbaryl & 1 & 0.024 & 0.024 & 2 \\
\hline & Methomyl & 1 & 0.038 & 0.038 & 2 \\
\hline Eggplant & Bifenthrin & 1 & 0.006 & 0.006 & 0.5 \\
\hline \multirow{3}{*}{ Celery } & Triadimefon & 1 & 0.013 & 0.013 & 0.1 \\
\hline & Carbaryl & 4 & 0.021 & 0.032 & 2 \\
\hline & Methomyl & 1 & 0.072 & 0.072 & 2 \\
\hline \multirow{3}{*}{ Lettuce } & Chlorpyrifos & 4 & 0.298 & 0.540 & 0.1 \\
\hline & Chlorothalonil & 4 & 0.305 & 0.930 & 5 \\
\hline & Methomyl & 2 & 0.032 & 0.044 & 2 \\
\hline \multirow{3}{*}{ Rape } & Triadimefon & 3 & 0.003 & 0.004 & 0.1 \\
\hline & Chlorothalonil & 1 & 0.010 & 0.009 & 5 \\
\hline & Methomyl & 1 & 0.023 & 0.023 & 2 \\
\hline
\end{tabular}

Table 5 Pesticide multi-residue in vegetables analyzed in November, 2009.

\begin{tabular}{|c|c|c|c|c|c|}
\hline Commodity & Pesticide & Detected number & Mean (mg/kg) & $\operatorname{Max}(\mathrm{mg} / \mathrm{kg})$ & MRL (mg/kg) \\
\hline \multirow{3}{*}{ Kidney bean } & Chlorothalonil & 1 & 0.002 & 0.001 & 5 \\
\hline & Carbaryl & 1 & 0.016 & 0.016 & 2 \\
\hline & Methomyl & 1 & 0.017 & 0.017 & 2 \\
\hline Chinese cabbage & Chlorothalonil & 1 & 0.001 & 0.001 & 5 \\
\hline Tomato & Chlorothalonil & 1 & 0.011 & 0.011 & 5 \\
\hline Cucumber & Chlorothalonil & 2 & 0.004 & 0.004 & 5 \\
\hline \multirow{2}{*}{ Cabbage } & Cypermethrin & 3 & 0.058 & 0.078 & 2 \\
\hline & Methomyl & 1 & 0.032 & 0.032 & 2 \\
\hline Eggplant & Chlorothalonil & 1 & 0.010 & 0.009 & 5 \\
\hline \multirow{4}{*}{ Celery } & Omethoate & 1 & 2.200 & 2.200 & 0 \\
\hline & Chlorpyrifos & 4 & 0.068 & 0.180 & 0.05 \\
\hline & Chlorothalonil & 1 & 0.780 & 0.780 & 5 \\
\hline & Methomyl & 2 & 0.017 & 0.018 & 2 \\
\hline Lettuce & Cypermethrin & 3 & 0.018 & 0.038 & 2 \\
\hline
\end{tabular}

Table 6 Pesticide multi-residue in vegetables analyzed in January, 2010.

\begin{tabular}{|c|c|c|c|c|c|}
\hline Commodity & Pesticide & Detected number & Mean $(\mathbf{m g} / \mathbf{k g})$ & Max $(\mathbf{m g} / \mathbf{k g})$ & MRL $(\mathbf{m g} / \mathbf{k g})$ \\
\hline Kidney bean & Cyhalothrin & 1 & 0.022 & 0.022 & 0.1 \\
\hline Tomato & Chlorothalonil & 1 & 0.081 & 0.081 & 5 \\
\hline \multirow{2}{*}{ Eggplant } & Chlorpyrifos & 1 & 0.030 & 0.030 & 0.5 \\
& Chlorothalonil & 1 & 0.021 & 0.021 & 5 \\
\hline \multirow{2}{*}{ Celery } & Chlorpyrifos & 1 & 0.260 & 0.260 & 0.099 \\
\hline
\end{tabular}

the qualifying rates of kidney bean and tomato reached to $100 \%$ in 2010, the results all meet the standards comparing with 2009 (kidney bean 94\%, tomato 96\%). However, lettuce (93\%-96\%) and rape (93\%-95\%) had a little effect on the qualifying rates from $2009-10$. Chinese cabbage (100\%) and green pepper $(86 \%$, $100 \%)$ were sampled only in November 2009 and April and July 2010, respectively.

Table 10 presents the distribution for all commodities from 200910 pesticide multi-residue monitoring programme. A total of 20 of all samples (5\%) had multi-residues above the MRLs. Multiresidues below the MRLs were found in 145 (35\%) samples. Multi-residues of pesticides for which there were no MRL were found in 255 (61\%) samples. Pesticide multi-residues were more frequently found in celeries ( 10 and $20 \%$, respectively) on Dalian market in 2009-10. To compare results of other vegetables, pesticide multi-residues were found in approximately $9 \%$ of green peppers, $6 \%$ of rapes, $5 \%$ of lettuces, $4 \%$ of kidney beans and $2 \%$ of tomatoes, respectively. 
Table 7 Pesticide multi-residue in vegetables analyzed in April, 2010.

\begin{tabular}{|c|c|c|c|c|c|}
\hline Commodity & Pesticide & Detected number & Mean (mg/kg) & $\operatorname{Max}(\mathrm{mg} / \mathrm{kg})$ & MRL (mg/kg) \\
\hline Cucumber & Chlorothalonil & 1 & 0.071 & 0.071 & 5 \\
\hline Eggplant & Chlorpyrifos & 1 & 0.022 & 0.022 & 0.5 \\
\hline Celery & Chlorpyrifos & 1 & 0.048 & 0.048 & 0.05 \\
\hline \multirow{4}{*}{ Green pepper } & Chlorpyrifos & 4 & 0.190 & 0.240 & 1 \\
\hline & Cypermethrin & 2 & 0.036 & 0.043 & 0.5 \\
\hline & Chlorothalonil & 1 & 0.018 & 0.018 & 5 \\
\hline & Carbofuran & 1 & 0.052 & 0.052 & 0 \\
\hline \multirow{2}{*}{ Lettuce } & Chlorpyrifos & 2 & 0.036 & 0.037 & 0.1 \\
\hline & Chlorothalonil & 3 & 0.004 & 0.007 & 5 \\
\hline Rape & Chlorpyrifos & 1 & 0.910 & 0.910 & 0.1 \\
\hline
\end{tabular}

Table 8 Pesticide multi-residue in vegetables analyzed in July, 2010.

\begin{tabular}{|c|c|c|c|c|c|}
\hline Commodity & Pesticide & Detected number & Mean (mg/kg) & $\operatorname{Max}(\mathrm{mg} / \mathrm{kg})$ & MRL (mg/kg) \\
\hline \multirow{2}{*}{ Eggplant } & Chlorothalonil & 1 & 0.050 & 0.050 & 5 \\
\hline & Cypermethrin & 1 & 0.110 & 0.110 & 0.5 \\
\hline \multirow{5}{*}{ Celery } & Parathion & 1 & 0.056 & 0.056 & 0 \\
\hline & Chlorothalonil & 1 & 1.530 & 1.530 & 5 \\
\hline & Carbofuran & 1 & 0.030 & 0.030 & 0 \\
\hline & Triadimefon & 2 & 0.011 & 0.012 & 0.1 \\
\hline & Chlorpyrifos & 2 & 0.031 & 0.036 & 0.05 \\
\hline Green pepper & Cyhalothrin & 1 & 0.010 & 0.010 & 0.2 \\
\hline \multirow{5}{*}{ Lettuce } & Triadimefon & 2 & 0.039 & 0.066 & 0.1 \\
\hline & Chlorothalonil & 2 & 2.425 & 4.840 & 5 \\
\hline & Cypermethrin & 3 & 0.076 & 0.140 & 2 \\
\hline & Chlorpyrifos & 1 & 0.230 & 0.230 & 0.1 \\
\hline & Cypermethrin & 1 & 0.054 & 0.054 & 2 \\
\hline \multirow{3}{*}{ Rape } & Chlorothalonil & 1 & 0.025 & 0.025 & 5 \\
\hline & Cyhalothrin & 1 & 0.099 & 0.099 & 0.2 \\
\hline & Deltamethrin & 1 & 0.340 & 0.340 & 0.5 \\
\hline
\end{tabular}

Table 9 Qualifying rate of random sampling in 2009-10.

\begin{tabular}{|c|c|c|c|c|c|c|c|}
\hline \multirow{2}{*}{ Commodity } & \multicolumn{7}{|c|}{ Qualifying rate (\%) } \\
\hline & January, 2009 & May, 2009 & September, 2009 & November, 2009 & January, 2010 & April, 2010 & July, 2010 \\
\hline Kidney bean & 88 & 100 & 88 & 100 & 100 & 100 & 100 \\
\hline Chinese cabbage & - & - & - & 100 & - & - & - \\
\hline Tomato & 100 & 86 & 100 & 100 & 100 & 100 & 100 \\
\hline Cucumber & 100 & 100 & 100 & 100 & 100 & 100 & 100 \\
\hline Cabbage & 100 & 100 & 100 & 100 & 100 & 100 & 100 \\
\hline Eggplant & 100 & 100 & 100 & 100 & 100 & 100 & 100 \\
\hline Celery & 43 & 83 & 100 & 40 & 100 & 100 & 82 \\
\hline Green pepper & - & - & - & - & - & 86 & 100 \\
\hline Lettuce & 100 & 100 & 71 & 100 & 100 & 100 & 89 \\
\hline Rape & 86 & 88 & 100 & 100 & 100 & 86 & 100 \\
\hline Total & 90 & 95 & 95 & 95 & 100 & 97 & 95 \\
\hline
\end{tabular}

In view of the total number of pesticides each time comparing the results of frequency of multi-residues (Figure 1), the frequency of multi-residues decreased from 74 to $40 \%$ during 2009-10 in overall samples. In detail, Chinese cabbage, eggplant, celery and rape had little fluctuation between the results from 2009-
10. A decreasing number of pesticide multi-residues for kidney bean, tomato, cucumber and cabbage were showed from 2009 to 2010. However, there was not a great deal of improvement in frequency of pesticide multi-residues in 2010 versus 2009 for green pepper and lettuce. 
Table 10 Distribution of samples from 2009-10 pesticide multi-residue monitoring programme.

\begin{tabular}{|c|c|c|c|c|}
\hline Commodity & Samples analysed & $\begin{array}{c}\text { Samples with residues } \\
\text { above the MRL }\end{array}$ & $\begin{array}{c}\text { Samples with residues } \\
\text { below the MRL }\end{array}$ & $\begin{array}{c}\text { Samples without } \\
\text { detected residues }\end{array}$ \\
\hline Kidney bean & 52 & $2(4 \%)^{\text {a }}$ & $10(19 \%)$ & $5(77 \%)$ \\
\hline Chinese cabbage & 6 & $0(0 \%)$ & $1(17 \%)$ & $33(77 \%)$ \\
\hline Tomato & 43 & $1(2 \%)$ & $9(21 \%)$ & $46(87 \%)$ \\
\hline Cucumber & 53 & $0(0 \%)$ & $10(19 \%)$ & $44(81 \%)$ \\
\hline Cabbage & 54 & $0(0 \%)$ & $16(36 \%)$ & $29(64 \%)$ \\
\hline Eggplant & 45 & $0(0 \%)$ & $30(61 \%)$ & $9(18 \%)$ \\
\hline Celery & 49 & $10(20 \%)$ & $8(73 \%)$ & $2(18 \%)$ \\
\hline Green pepper & 11 & $1(9 \%)$ & $36(65 \%)$ & $16(29 \%)$ \\
\hline Lettuce & 55 & $3(5 \%)$ & $18(35 \%)$ & $31(60 \%)$ \\
\hline Rape & 52 & $3(6 \%)$ & $145(35 \%)$ & $255(61 \%)$ \\
\hline All samples & 420 & $20(5 \%)$ & & $76)$ \\
\hline
\end{tabular}

${ }^{a}$ Number of samples. Values in parentheses are the percent of samples.

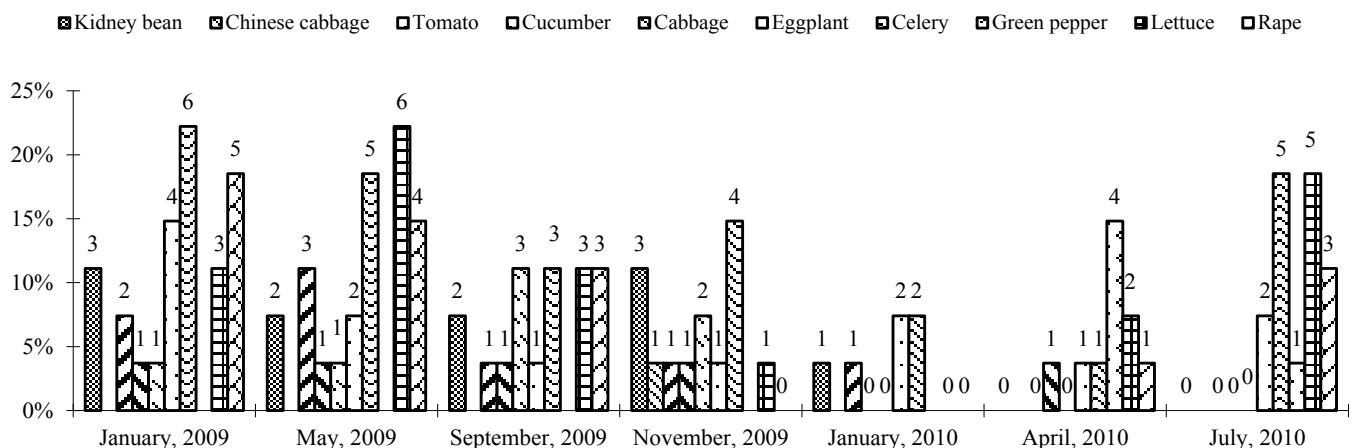

Figure 1 Frequency of multi-residues in vegetables in 2009-10.

\section{Conclusions}

The monitoring programme for 2009 and 2010 on Dalian market covered 420 samples of 10 different vegetables. The samples were analysed for 27 pesticides of which 7 (carbofuran, methamidophos, aldicarb, omethoate, carbofuran, chlorpyrifos and cypermethrin) were detected in the samples. Pesticides were easier to keep on celery, rape, lettuce and kidney bean than the other vegetables. Comparatively speaking, owing to more

\section{References}

1 Botitsi H, Economou A, Tsipi D (2007) Development and validation of a multi-residue method for the determination of pesticides in processed fruits and vegetables using liquid chromatographyelectrospray ionization tandem mass spectrometry. Anal Bioanal Chem 389: 1685-1695.

2 Cervera MI, Medina C, Portolés T, Pitarch E, Beltrán J, et al. (2010) Multi-residue determination of 130 multiclass pesticides in fruits and vegetables by gas chromatography coupled to triple quadrupole tandem mass spectrometry. Anal Bioanal Chem 397: 2873-2891.

3 Farajzadeh MA, Hatami M (2004) Solid-phase microextraction gas chromatography for determination of some organophosphorus pesticides. Chromatographia 59: 259-262.

4 Fu L, Liu SY, Xu FX (2017) Effect of treatment with MeJA on physiology plant diseases and insect pests in summer, the qualifying rates of samples in winter are higher than in summer. Though the period of the survey is only 2 years, the overall situation of vegetables is of high quality and has little fluctuation per year.

\section{Acknowledgments}

This work was supported by China Spark Program Project (2015GA650007) and College Student Innovation and Entrepreneurship Training Program (201710166218).

and biochemistry in blueberry fruit. Journal of Shenyang Normal University 35: 473-475.

5 Hou B, Yang J, Wu LH (2010) Literature review of the effects of pesticide residue on agri-food safety, farmers' perception on pesticide residue and the influencing factors. Journal of Anhui Agri 38: 2098-2101.

6 Poulsen ME, Andersen JH (2003) Results from the monitoring of pesticide residues in fruit and vegetables on the Danish market, 2000-01. Food Additives and Contaminants 20: 742-757.

7 Ruiz S, Arcas N, Cuestas P (2001) Consumer attitudes towards ecological agrarian fruits and vegetables in Spain. A segmentation approach. Acta Horticulturae 559: 681-686.

8 Sadło S, Szpyrka E, Jaźwa A, Zawiślak A (2007) Pesticide Residues in Fruit and Vegetables from Southeastern Poland, 2004-05. Polish J Environ Stud 16: 313-319. 